of abdominal symptoms was more than twice as great as that in a matched control group who had not had recurrent abdominal pains as children.

Interestingly, 11 of the 18 with persistent abdominal symptoms had an extended period in adolescence without symptoms-they grew out of it-and then subsided into it again. The severity of symptoms in 5 of the 18 was sufficient to interfere with normal active life. In addition 11 of the 34 had other symptoms ranging from migraine, headaches, and back pain to "bad nerves." Once again this was a higher incidence than in the control group.

In general it seems that despite sympathetic management in childhood about half the children with recurrent abdominal pain will have troublesome abdominal symptoms as adults. Clearly the syndrome is not as benign as has been suggested. Reassurance and symptomatic treatment may help the child at the time, and also help the family, but it does not necessarily alter the long-term prognosis. ${ }^{4}$ An important aim in the medical care of children is to prevent childhood conditions from interfering with normal development and adult health. At present this aim is not achieved in the management of the large numbers of children with recurrent abdominal pain. There is a need for further research into the causes of the syndrome and for therapeutic trials in the hope that we may be able to prevent little bellyachers becoming big bellyachers.

1 Apley, J., and Naish, N., Archives of Disease in Childhood, 1958, 33, 165. 2 Apley, J., The Child With Abdominal Pains. Oxford, Blackwell Scientific Publications, 1959.

3 Apley, J., and MacKeith, R., The Child and his Symptoms, 2nd edn. Oxford, Blackwell Scientific Publications, 1968.

4 Apley, J., and Hale, B., British Medical fournal, 1973, 3, 7

5 Apley, J., and Hale, B., British Medical fournal, 1973, 3, 7.

6 Christensen, M. F., and Mortensen, O., Archives of Disease in Childhood, $1974,50,110$.

\section{Chronic Paronychia}

Chronic paronychia is a common enough clinical problem, yet failure of response to treatment is a recurrent source of dismay to patient and doctor alike. The condition is most often seen in housewives, nurses, cleaners, or others who often have their hands in water. There is a moderately inflamed swelling over the nail matrix and down one or both sides of the nail; several fingers may be affected. Occasional episodes occur of more acute inflammation and pain, and over the course of time the nail plate itself becomes distorted and sometimes discoloured, usually with transverse ridging.

Recent research interest has been concerned mostly with the microbiological features of the lesion and with treatment directed against the infection, but success in treatment depends more on an understanding of the anatomical and behavioural factors in pathogenesis. The organism most commonly found is Candida albicans, though other Candida species are also common, as are the bacteria of the gut flora; Pseudomonas aeruginosa is responsible for blue-green discolouration of the nail plate; Staphylococcus pyogenes is found especially in episodes of acute and painful exacerbation. ${ }^{1}$ A recent epidemiological study ${ }^{2}$ of the sources and spread of $C$. albicans in chronic paronychia in Israeli women showed that the source of the yeast was usually the mouth or bowel (but not the vagina) of the patient or a member of her family; it also showed that the middle finger of the dominant hand was usually affected first, followed by an adjacent finger or the equivalent finger on the other hand.
C. albicans and the associated bacteria are not, however, primary pathogens, and it is their propensity for colonizing moist skin folds that brings them into prominence in this condition just as it does in submammary or groin intertrigo in obese subjects, or in perlèche due to habitual licking, or to infolding of the corners of the mouth after dental clearance, or simply because of fat cheeks. In all these conditions it is important for the doctor and the patient to understand the parts played by moisture, warmth, and friction in providing an environment suitable for invasion by common and usually harmless organisms.

Patients should be discouraged from fiddling with their nail folds-for instance by detaching the cuticle and pushing it back, thereby opening up a space and introducing organisms at the same time. A similar manoeuvre by the doctor, using a sharpened orange stick dipped in phenol or gentian violet may be therapeutic once the condition has developed, but management should be directed more towards prevention. While it is impossible for affected patients altogether to avoid immersing their hands in water, they should be told to keep such immersion to a minimum. If rubber gloves are worn for washing clothes or dishes they should be removed after about ten minutes and the hands dried, as prolonged wearing gives rise to a very humid, warm climate within the gloves. While the hands are dry, both before immersion in water and as soon after as possible, nystatin ointment can be rubbed gently into the nail folds to act against any yeasts already present and as a barrier against further invasion. Though this may mean more than a dozen applications a day it is important that the patient understands that that is what the doctor intends. During episodes of acute exacerbation gentamicin ointment may be used, with a course of an oral antibiotic such as erythromycin. ${ }^{1}$ Resolution usually takes several weeks or even months, but slow progress should not discourage the patient or her doctor from persisting with treatment and-more important in the long run-with the appropriate preventive measures.

${ }^{1}$ Barlow, A. J. E., et al., British fournal of Dermatology, 1970, 82, 448.

2 Ganor, S., and Pumpianski, R., British fournal of Dermatology, 1974, 90, 77.

\section{Never Forget Syphilis}

Our forefathers saw a great deal of syphilis in all its manifestations, but experienced physicians were well aware of the ability of the disease to deceive and advised their contemporaries never to forget it. Mistakes occurred, because infection was apt to remain latent for years, and when manifestations occurred they were quite likely to resemble those of other diseases. A further handicap, which still persists, is that syphilis was regarded as a disgrace as well as a disease, and physicians who liked and respected their patients suffered in this matter from what Stokes' called "a low index of suspicion." By comparison syphilis is now an uncommon disease, at any rate in Britain, and generations of doctors are unfamiliar with its manifestations and perhaps unaware of its pitfalls. Nevertheless, it still occurs, and its early stages are being found a little more often. With modern ease of communications and the modern tendency towards readier acceptance of intercourse outside marriage it may be that the disease will again become much more common. 